\title{
Temperament and character traits associated with the use of alcohol, cannabis, cocaine, benzodiazepines, and hallucinogens: evidence from a large Brazilian web survey
}

\author{
Ricardo Schneider Jr., ${ }^{1}$ Gustavo L. Ottoni, ${ }^{2}$ Hudson W. de Carvalho, ${ }^{3}$ Elaine Elisabetsky, ${ }^{1}$ \\ Diogo R. Lara ${ }^{2}$ \\ ${ }^{1}$ Department of Pharmacology and Graduate Program in Neurosciences, Universidade Federal do Rio Grande do Sul (UFRGS), Porto Alegre, \\ RS, Brazil. ${ }^{2}$ School of Biosciences, Pontifícia Universidade Católica do Rio Grande do Sul (PUCRS), Porto Alegre, RS, Brazil. ${ }^{3}$ School of \\ Psychology, Universidade de Federal de Pelotas (UFPEL), Pelotas, RS, Brazil.
}

\begin{abstract}
Objectives: To evaluate how personality traits are associated with occasional use, abuse, and dependence of alcohol, cannabis, cocaine, benzodiazepines, and hallucinogens in a large availability sample of adults via online questionnaires.

Methods: The sample consisted of 8,646 individuals ( $24.7 \%$ men and $75.3 \%$ women) who completed an anonymous web survey. Involvement with drugs and temperament/character traits were assessed through the Alcohol, Smoking and Substance Involvement Screening Test (ASSIST) and the Temperament and Character Inventory - Revised (TCI-R), respectively. Interactions among variables were analyzed using MANOVA with Bonferroni adjustment.

Results: Novelty seeking was the trait most associated with increased involvement with alcohol, cannabis, and cocaine. There was a significant association between harm avoidance and benzodiazepine use. Persistence was lower in cannabis-, benzodiazepine-, and cocaine-dependent subjects, as well as in hallucinogen abusers. Self-directedness was reduced in dependents of all drug classes. No strong relationships were found between other temperament or character dimensions and the severity of drug use.

Conclusions: Novelty seeking was associated with increased involvement with all drugs studied in this sample, although to a lesser extent with benzodiazepines and hallucinogens. The temperament and character profile for benzodiazepine use was different from that of other drugs due to the relationship with higher harm avoidance and self-transcendence and lower self-directedness.
\end{abstract}

Keywords: Alcohol abuse; psychoactive substance use disorder; other psychological issues; tests/ interviews, psychometric; computers

\section{Introduction}

Personality and temperament traits are psychobiologicaldispositional dimensions that influence behavior, mood, and cognitive patterns in relatively stable and consistent ways. ${ }^{1,2}$ These traits are considered to be central constructs in the understanding of normal and pathological individual differences and general adaptation. ${ }^{3,4} \mathrm{~A}$ major theme in the field has been the association of personality and temperament traits with psychoactive substance use, abuse, and addiction. ${ }^{5-7}$

The connection of personality and temperament traits with harmful patterns of drug use has been well documented. ${ }^{5,6,8}$ In general terms, traits related to appetitive and unconstrained behavioral tendencies have

Correspondence: Diogo Rizzato Lara, Faculdade de Biociências, PUCRS, Av. Ipiranga, 6681, prédio 12A, CEP 90619-900, Porto Alegre, RS, Brazil.

E-mail: drlara@pucrs.br

Submitted Jan 02 2014, accepted Apr 292014. been identified in the personality profile of subjects with harmful patterns of substance use and general externalizing problems..$^{9-12}$ Among the constellation of traits related to appetitive and unconstrained dispositions, two have gained particular attention in the literature: novelty seeking (NS) ${ }^{8}$ and sensation seeking (SS). ${ }^{13}$ Both of these traits have been considered major personality variables when related to alcohol and drug consumption for empirical and conceptual reasons. ${ }^{14,15}$ Higher scores in these traits have been reported in users of cocaine, ${ }^{16,17}$ alcohol, ${ }^{8,18,19}$ heroin, ${ }^{20,21}$ tobacco, ${ }^{22}$ and even cola drinks, although not for coffee. ${ }^{23}$ The biological underpinnings related to drug-seeking behavior, ${ }^{24}$ externalizing tendencies, ${ }^{25} \mathrm{NS},{ }^{26}$ and $\mathrm{SS}^{13}$ are highly overlapping and generally associated with dysregulation of the frontal cortex and of the mesolimbic dopamine system.

Other personality and temperament traits associated with various high health risk behaviors, including harmful substance use, are low levels of harm avoidance (HA), traditionalism, persistence (PS), and control and high levels of alienation, aggression, and irritability. ${ }^{9}$ 
Nevertheless, some particularities may arise depending on the type of substance. Spalleta et al. ${ }^{27}$ found that higher HA, NS, and reward dependence (RD) scores and lower PS and self-directedness (SD) scores are associated with cannabis use. ${ }^{27}$ They also showed that the NS facet of exploratory excitability was higher in individuals with occasional cannabis use and abuse than in those who never used it. In addition, subjects with occasional use, abuse, and dependence patterns of cannabis use scored significantly higher than the no-use group in regard to the NS facets of impulsiveness, extravagance, and disorderliness. ${ }^{27}$ Cloninger $^{8}$ proposed that type 1 alcoholism is characterized by more anxiety-related traits, such as lower NS and higher HA, whereas type 2 alcoholics, characterized by binge drinking, show the opposite pattern.

Nevertheless, methodological limitations are systematically present in this field of investigation. Most studies associating personality and temperament traits with harmful substance use have been conducted in casecontrol designs, in which the mean score in a specific trait (mostly NS and SS) is compared between two sample groups: one composed of heavy users of a single drug and the other composed of non-users/occasional users. $^{6,17}$ This approach does not allow simultaneous examination of personality/temperament trait profiles related to drug type (i.e., alcohol, cocaine, amphetamine) and to the degree of drug involvement (drug experimentation, occasional use, abuse, and dependence). Furthermore, the identification of personality traits associated with benzodiazepine and hallucinogen use has been poorly characterized.

Cloninger's model ${ }^{26}$ is considered to be a major framework for understanding individual differences in a continuum from normality to psychopathology. It comprises four temperament dimensions - HA, NS, RD, and PS - and three character dimensions - SD, cooperativeness (CO), and self-transcendence (ST) - that can be evaluated with the Temperament and Character Inventory - Revised (TCl-R). Recently, NS traits were suggested as a general risk factor for addiction, whereas other traits (e.g., HA, low SD) would be more specific for a particular choice of drug (e.g., HA for alcoholism, low SD for opiate addiction). ${ }^{28}$

The present study aims to advance the characterization of temperament and personality trait patterns of cannabis, alcohol, benzodiazepine, cocaine, and hallucinogen users as assessed by Cloninger's psychobiological model of temperament and character. ${ }^{26}$ Additionally, we evaluated the temperament and character profiles associated with each specific drug (e.g., cannabis) while controlling for the use of other drugs (e.g., cocaine, hallucinogens, and benzodiazepines).

Based on previous studies ${ }^{14,15}$ and on conceptual grounds, ${ }^{25,26}$ the hypotheses of this study were: NS would be a general predictor of substance experimentation, use, abuse and dependence; HA would be diminished in general in substance abusers and dependents; and ST would be higher among subjects with greater cannabis and hallucinogen involvement.

\section{Methods}

\section{Study design}

This is a cross-sectional web survey designed to assess a wide range of constructs related to personality/ temperament traits, psychopathology, and other behavioral indicators. The project was named the Brazilian internet Study on Temperament and Psychopathology (BRAINSTEP), and its design is described in further detail in Lara et al. ${ }^{29}$

\section{Participants and procedures}

Participants responded voluntarily to the internet versions of instruments adapted to Brazilian Portuguese, including the TCI- $\mathrm{R}^{30}$ and the ASSIST. ${ }^{31}$ To motivate participation, our web survey (www.temperamento.com.br) was publicized on national TV news and in local newspapers and personalized feedback on the respondent's temperament profile upon completion of the survey was offered.

Before responding to the scales and questionnaires that comprise BRAINSTEP, all participants provided electronic informed consent to comply with the requirements of the National Health Council of Brazil (Resolution 196/1996) and the Code of Ethics of the World Medical Association (Declaration of Helsinki). The study was approved by the Institutional Review Board of Hospital São Lucas from Pontifícia Universidade Católica do Rio Grande do Sul and the Ethics Council of the Institute of Basic Health Sciences of Universidade Federal do Rio Grande do Sul, Brazil.

Inclusion criteria for this study were age $\geqslant 18$ and $<80$ years and adequate answers to validity checks that assessed attention and consistency of responses. The initial sample was composed of 12,225 participants, but 3,579 failed the validity checks across the system and in the TCl-R. The final sample consisted of 8,646 participants, with $2,135(24.7 \%)$ men with a mean age of $36.3 \pm 12.5$ years and $6,111(75.3 \%)$ women with a mean age of $34.7 \pm 11.4$ years. In terms of educational profile, $69(0.8 \%)$ participants claimed to have an incomplete and $59(0.7 \%)$ a complete primary education, $276(3.2 \%)$ to have an incomplete and 1,450 (16.8\%) a complete secondary education, $2,119(24.5 \%)$ to have an incomplete and 2,781 (32.2\%) a complete higher education (university degree), 1,757 (20.3\%) to have a specialization or master's degree, and $135(1.6 \%)$ a doctoral degree.

\section{Instruments}

The TCl-R is a 240-item self-report questionnaire (including five validity items) designed to assess four temperament dimensions (HA, NS, RD, and PS) and three character dimensions (SD, CO, and ST). Each dimension is composed of three to five facets corresponding to five to ten questions scored on a 7-point Likert scale. The Brazilian Portuguese version of the TCl$\mathrm{R}$ has been previously validated, ${ }^{30}$ and there was evidence of very good internal consistency reliability of 
the TCl-R on our website, as denoted by Cronbach's alpha values $>0.80$ for all scales. ${ }^{29}$

The ASSIST consists of a questionnaire designed to evaluate the use of psychoactive substances (alcohol, tobacco, cocaine, cannabis, stimulants, sedatives, inhalants, hallucinogens, and opiates) in terms of frequency (lifetime and during the last 3 months), drug-use related problems (financial, social, legal, and health issues), concern of others regarding the individual's pattern of use, unsuccessful attempts to stop or reduce drug use, craving patterns, and injectable drug use. Question 1 evaluates the experimentation of each drug (never used to daily or almost daily use). Scores from 0 to 4 are attributed to questions 2 to 5 , while for questions 6 and 7 , scores range from 0 to 2 . The highest possible score is 20 , where 0 is attributed to someone who never used the substance; $1-3$ is indicative of occasional use; $4-15$ is suggestive of abuse; and scores higher than 15 are suggestive of addiction. Based on these guidelines, individuals with occasional drug use have tried at least one drug (lifetime or in the last 3 months prior to assessment), but did not experience any negative outcome related to drug use. Participants categorized with substance abuse may be current users or not who have experimented with one or more drugs and may have had some degree of drug-related problems or frustrated trials to reduce drug intake. Finally, individuals categorized with substance addiction show current patterns of drug use, drug-related problems, and failed attempts to reduce drug use.

\section{Statistical analysis}

Skewness and kurtosis values were used as normality tests (skewness $<2$ and kurtosis $<7$ ) and attested the suitability of parametric statistics. Sex-related differences in drug choice were assessed using a t-test for independent samples based on ASSIST total scores for each drug. Age differences for each category of drug use were assessed using univariate analysis of variance (one-way ANOVA). Associations between temperament and character traits and patterns of substance use were analyzed with multivariate analysis of covariance (MANCOVA) followed by Bonferroni adjustment (95\% confidence intervals $[95 \% \mathrm{Cl}]$ ) and controlling for age, sex, and ASSIST scores for the other drugs of abuse. Effect sizes for standardized mean differences (Cohen's d score) were calculated for each drug use group (alcohol, cannabis, etc.). Cohen's d score values $<0.3$ are considered to be indicative of low effect size, around 0.5 are interpreted as indicative of moderate effect size, and $\geqslant 0.8$ are regarded as indicative of high effect size. ${ }^{32}$

\section{Results}

\section{Sex and age effects}

According to the total ASSIST scores, men more often use, abuse, and become dependent on alcohol $\left(t_{8.644}=15.6\right.$, $p<0.01)$, cannabis $\left(t_{8.644}=9.13, p<0.01\right)$, cocaine $\left(t_{8.644}=10.16, p<0.01\right)$, and hallucinogens $\left(t_{8.644}=6.68\right.$, $p<0.01)$. In contrast, benzodiazepine use scores were significantly higher for women than for men $\left(t_{8.644}=3.68\right.$, $p<0.01)$. Regarding age, cannabis and cocaine users were younger than non-users $\left(p<0.001, F_{3,8.645}=35.1\right.$, $F_{3,8.645}=11.3$, respectively), while benzodiazepine users were older than those who never used it $\left(F_{3,8.645}=85.5\right.$, $p<0.01)$. None of the subjects reached the dependence score for hallucinogens. Since the association of patterns of drug use with personality traits was generally similar for men and women, the following data are shown for the whole sample. Table 1 shows the proportion of participants and the sample age distribution according to drug type and patterns of drug use.

\section{Associations of temperament and character traits with patterns of drug use}

\section{Alcohol (Figures 1A and 1B)}

Individuals with occasional use and abuse patterns presented a moderate decrease in HA scores as compared with participants with no use or with alcohol dependence $\left(F_{3,8.637}=30.3, p<0.01, d=0.32\right)$. NS scores were significantly different among all patterns of use, showing a moderate effect size $\left(\mathrm{F}_{3,8.637}=37.0\right.$, $p<0.01, d=0.51)$. The higher the alcohol consumption, the higher the NS score. Alcohol abusers were slightly more reward-dependent than those who never used it and occasional users $\left(F_{3,8.637}=10.3, p<0.01\right)$. SD $\left(F_{3,8.637}=28.8, p<0.01, d=0.15\right)$ and $C O\left(F_{3,8.637}=12.0\right.$, $\mathrm{p}<0.01, \mathrm{~d}=0.44$ ) were only significantly and moderately reduced in those with alcohol dependence (Figure 1B). PS and ST were not different between groups $(p>0.05)$.

\section{Cannabis (Figures $2 \mathrm{~A}$ and $2 \mathrm{~B}$ )}

Occasional users and participants with evidence of cannabis abuse scored significantly lower for HA than those who never used it $\left(F_{3,8.637}=11.8, p<0.01\right.$, $\mathrm{d}=0.21$ ). NS scores were significantly and moderately higher in participants with cannabis occasional use, abuse, and dependence as compared with no use $\left(F_{3,8.637}=35.3, p<0.01, d=0.55\right)$. Participants with occasional use and dependence patterns had higher $\mathrm{RD}$ scores as compared with those who never used it $\left(F_{3,8.637}=5.1, p<0.05, d=0.1\right)$, whereas participants with cannabis dependence scored significantly lower for PS as compared with those with no use and occasional user $\left(F_{3,8.637}=6.8, p<0.05, d=0.5\right)$. SD was slightly but significantly lower for individuals with cannabis dependence as compared with all other groups $\left(\mathrm{F}_{3,8.637}=6.4\right.$, $p<0.01, d=0.11)$. CO and ST showed no relevant differences.

\section{Benzodiazepines (Figures $3 \mathrm{~A}$ and $3 \mathrm{~B}$ )}

HA scores increased substantially with higher benzodiazepine use, with significant differences among all groups $\left(F_{3,8.637}=89.8, p<0.01, d=0.8\right)$. NS scores were significantly higher for benzodiazepine occasional users and for participants with abuse and dependence scores when compared to those with no use $\left(F_{3,8.637}=14.6\right.$, 
Table 1 Proportion of participants' sex and age according to drug type and pattern of use

\begin{tabular}{|c|c|c|c|c|}
\hline \multirow[b]{2}{*}{ Substance/patterns of use } & \multirow[b]{2}{*}{ n (\%) } & \multirow[b]{2}{*}{ Age, mean $\pm S D$} & \multicolumn{2}{|c|}{ Sex (\%) } \\
\hline & & & Male & Female \\
\hline \multicolumn{5}{|l|}{ Alcohol } \\
\hline No use & $1,513(17.5)$ & $36.6 \pm 12.2$ & 11.3 & $19.5^{*}$ \\
\hline Occasional use & $3,916(45.3)$ & $34.2 \pm 8.4$ & $37.8^{*}$ & 47.7 \\
\hline Abuse & $3,012(34.8)$ & $35.4 \pm 11.8$ & $46.5^{*}$ & 31.0 \\
\hline Dependence & $205(2.4)$ & $35.7 \pm 11.3$ & $4.3^{*}$ & 1.7 \\
\hline \multicolumn{5}{|l|}{ Cannabis } \\
\hline No use & $6,776(78.4)$ & $35.7 \pm 12.2^{*}$ & 71.9 & $80.5^{*}$ \\
\hline Occasional use & $1,536(17.8)$ & $33.4 \pm 9.6$ & $22.1^{*}$ & 16.3 \\
\hline Abuse & 289 (3.3) & $30.1 \pm 9.6$ & $5.1 *$ & 2.8 \\
\hline Dependence & $45(0.5)$ & $32.9 \pm 8.3$ & $0.9^{*}$ & 0.4 \\
\hline \multicolumn{5}{|l|}{ Benzodiazepines } \\
\hline No use & $6,833(79)$ & $34.1 \pm 11.4^{*}$ & $82.3^{*}$ & 78.0 \\
\hline Occasional use & $947(11)^{\prime}$ & $37.9 \pm 11.9$ & 9.1 & $11.5^{*}$ \\
\hline Abuse & $722(8.4)$ & $39.9 \pm 12.2$ & 7.2 & $11.7^{*}$ \\
\hline Dependence & $144(1.7)$ & $39.2 \pm 11.1$ & 1.4 & $1.8^{*}$ \\
\hline \multicolumn{5}{|l|}{ Cocaine } \\
\hline No use & $8,059(93.2)$ & $35.3 \pm 11.9 *$ & 88.4 & $94.8^{*}$ \\
\hline Occasional use & $500(5.8)$ & $33.0 \pm 9.1$ & $9.3^{*}$ & 4.6 \\
\hline Abuse & $72(0.8)$ & $30.5 \pm 7.4$ & $1.9 *$ & 0.5 \\
\hline Dependence & $16(0.2)$ & $28.5 \pm 7.2$ & $0.4^{*}$ & 0.1 \\
\hline \multicolumn{5}{|l|}{ Hallucinogens } \\
\hline No use & $8,354(96.6)$ & $35.2 \pm 11.8$ & 94.4 & 97.3* \\
\hline Occasional use & 274 (3.2) & $31.1 \pm 9.3$ & $5.2^{*}$ & 2.5 \\
\hline Abuse & $18(0.2)$ & $28.1 \pm 10.5$ & $0.4^{*}$ & 0.2 \\
\hline
\end{tabular}

$\mathrm{SD}=$ standard deviation.

* Indicates significant mean differences at $p<0.05$.

$p<0.01, d=0.35$ ). PS scores were significantly lower in individuals with benzodiazepine dependence. SD decreased with higher benzodiazepine use, with significant differences among all groups, except between individuals with occasional use and abuse patterns $\left(F_{3,8.637}=94.4, p<0.01, d=0.37\right)$. Regarding $\mathrm{CO}$, lower scores were observed in individuals with occasional use, abuse, and dependence scores as compared with those with no use, and in participants with dependence scores as compared with occasional users $\left(F_{3,8.637}=\right.$ $39.5, p<0.01, d=0.36)$. ST scores were significantly higher among participants with a benzodiazepine dependence pattern than in those who never used it and those with other use patterns $\left(F_{3,8.637}=6.7, p<0.01, d=0.37\right)$.

\section{Cocaine (Figures 4A and 4B)}

NS scores increased with higher use of cocaine, with a significant difference among all groups, except between those with evidence of cocaine abuse and those with dependence $\left(F_{3,8.637}=18.8, p<0.01, d=0.49\right)$. Individuals with a dependence use pattern had significantly and substantially lower PS scores than subjects who never used it and occasional users $\left(F_{3,8.637}=3.1\right.$, $p<0.05, d=0.75$ ). Participants with cocaine abuse and dependence had lower SD scores than those with no use $\left(F_{3,8.637}=9.1, p<0.01, d=0.60\right)$. CO scores of participants with cocaine abuse patterns were slightly lower than those with no use and occasional use $\left(F_{3,8637}=8.8, p<0.01, d=0.23\right) . H A$ and $S T$ were not significantly different across groups $(p>0.05)$.
Hallucinogens (Figures 5A and 5B)

Occasional users had significantly lower HA scores than those who never used hallucinogens $\left(F_{2,8.637}=3.9\right.$, $p<0.05, d=0.17$ ). Individuals with hallucinogens abuse pattern had significantly lower scores of PS when compared to those with no use $\left(F_{2,8.637}=5.3, p<0.05\right.$, $\mathrm{d}=0.67$ ). SD was significantly higher in occasional use when compared to no use $\left(F_{2,8.637}=4.4, p<0.05\right.$, $\mathrm{d}=0.26)$. ST was significantly higher in participants with scores consistent with hallucinogens abuse than in those with no use $\left(F_{2,8.637}=3.5, p<0.05, d=0.58\right)$. The results of other dimensions were non-significant.

\section{Associations of facets of NS with patterns of drug use}

Analysis of NS facets showed that: individuals with alcohol abuse and dependence scored higher on impulsiveness $\left(F_{3,8.637}=34.6, p<0.01, d=0.16\right)$, extravagance $\left(F_{3,8.637}=36.8, p<0.01, d=0.46\right)$, and disorderliness $\left(F_{3,8.637}=36.1, p<0.05, d=0.41\right)$ than those with no use, but with no difference in exploratory excitability (Figure $6 \mathrm{~A})$; participants with cannabis occasional use and abuse scored higher than those with no use on exploratory excitability, and participants with occasional use $\left(F_{2,8.637}=14.3, p<0.01, d=0.43\right)$, abuse, and dependence scored significantly higher than those with no use on impulsiveness $\left(F_{3,8.637}=15.3, p<0.01, d=\right.$ $0.27)$, extravagance $\left(F_{3,8.637}=12.2, p<0.01, d=0.30\right)$, and disorderliness $\left(F_{3,8.637}=28.1, p<0.01, d=0.29\right)$ (Figure 6B); benzodiazepine occasional use, abuse, and 
A - ALCOHOL

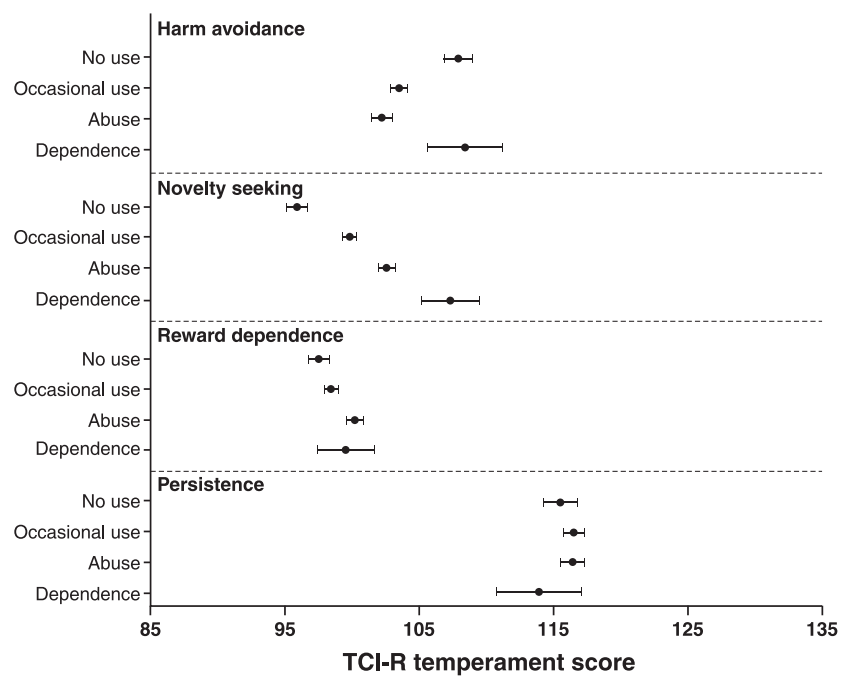

B - ALCOHOL

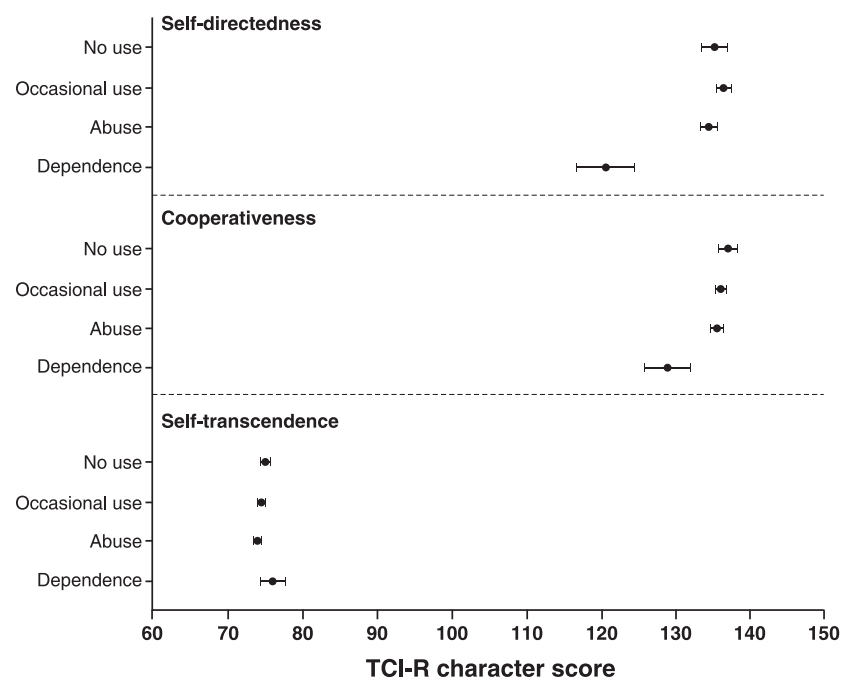

Figure 1 Temperament and character mean scores (dots) and Bonferroni-corrected 95\% confidence intervals (bars) in relation to patterns of alcohol involvement. TCl- $\mathrm{R}=$ Temperament and Character Inventory - Revised.

dependence groups scored lower than no use in exploratory excitability $\left(F_{3,8.637}=13.5, p<0.01, d=0.29\right)$, impulsiveness $\left(F_{3,8.637}=21.2, p<0.01, d=0.48\right)$, and extravagance $\left(F_{3,8.637}=27.2, p<0.01, d=0.50\right)$, and those in the abuse and dependence groups scored higher on disorderliness $\left(F_{3,8.637}=11.3, p<0.01, d=0.33\right)$ (Figure 6C); and participants with cocaine abuse and dependence scored slightly higher on impulsiveness $\left(\mathrm{F}_{3,8.637}=12.1, \mathrm{p}<0.01, \mathrm{~d}=0.22\right)$ and substantially higher on disorderliness $\left(F_{3,8.637}=5.6, p<0.05, d=0.76\right)$ and extravagance $\left(F_{3,8.637}=17.0, p<0.01, d=0.8\right)$ as compared with those with no use (Figure 6D).

\section{A - CANNABIS}

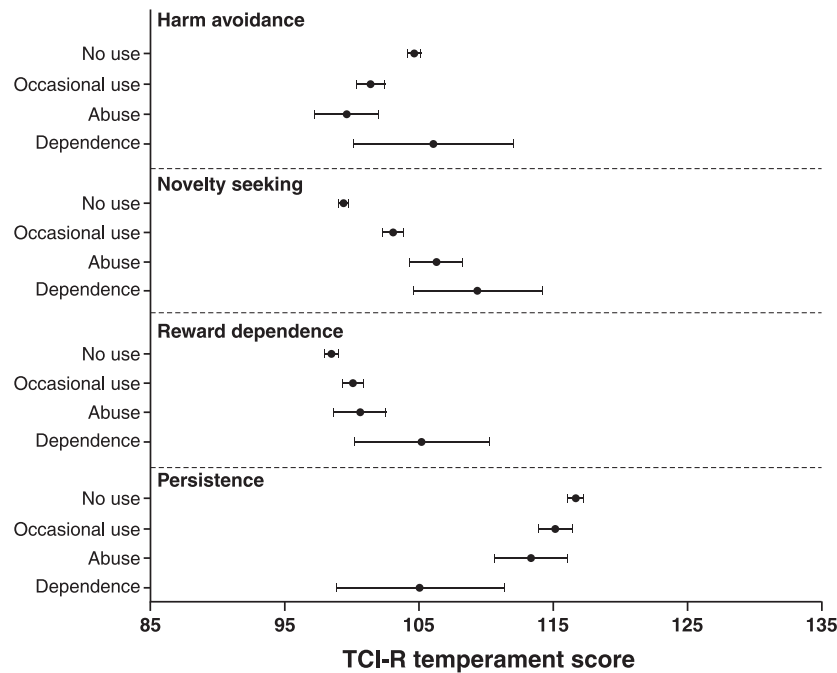

\section{Discussion}

Associations of substance use patterns with sex and age revealed that men use, abuse, and become addicted to all assessed substances (alcohol, cannabis, cocaine, and hallucinogens) more often than women. The exception was benzodiazepine use, which showed the opposite pattern. These findings are in accordance with epidemiological data showing that men are more prone to substance use disorders and general externalizing problems, ${ }^{33-35}$ while women are more prone to depressive and anxiety disorders. ${ }^{36}$ Our data also confirmed that

\section{B - CANNABIS}

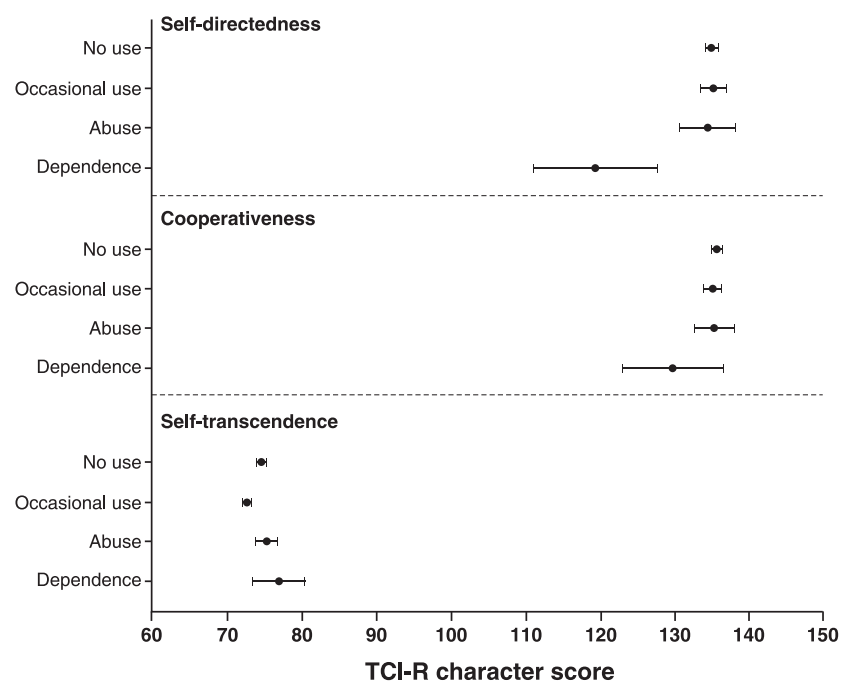

Figure 2 Temperament and character mean scores (dots) and Bonferroni-corrected 95\% confidence intervals (bars) in relation to patterns of cannabis involvement. TCI-R $=$ Temperament and Character Inventory - Revised. 


\section{A - BENZODIAZEPINES}

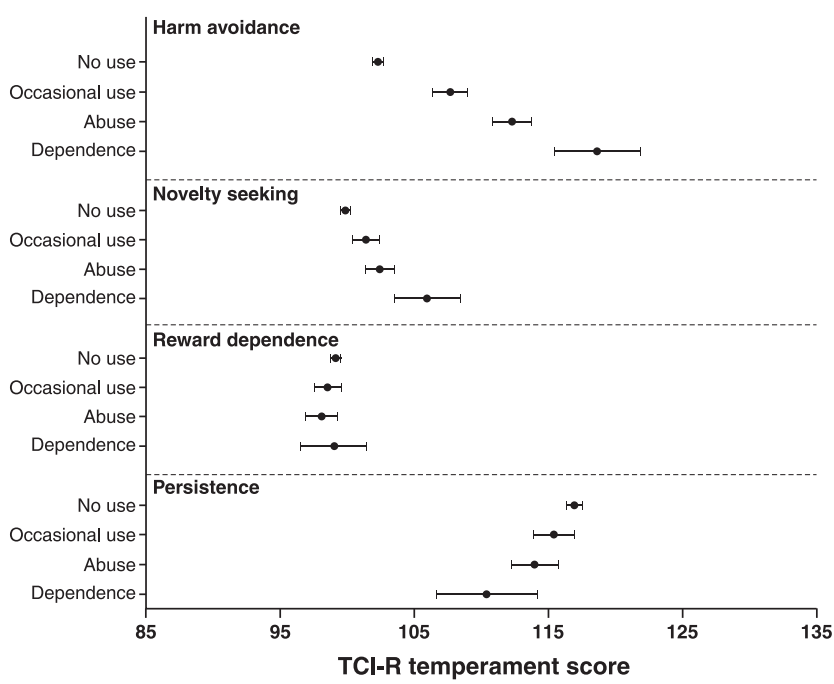

\section{B - BENZODIAZEPINES}

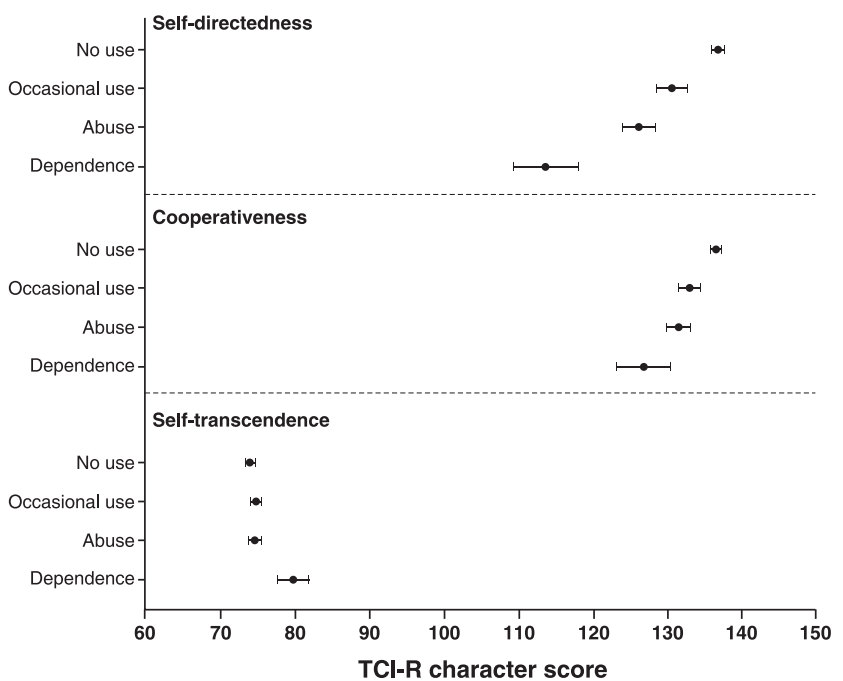

Figure 3 Temperament and character mean scores (dots) and Bonferroni-corrected 95\% confidence intervals (bars) in relation to patterns of benzodiazepine involvement.

people who use cannabis and cocaine tend to be younger than those who have never used these substances, which may be due to two factors: first, substance use increases from generation to generation ${ }^{34}$; and second, the onset of illegal substance use is concentrated among young adulthood (around 20 years of age). ${ }^{34}$ Nevertheless, only part of those who experiment with drugs continue to use them.

Data regarding the associations between patterns of substance use and traits partially corroborated the findings reported in the literature and our initial hypotheses. NS was associated, at a consistent, moderate degree, with general substance use at all levels of severity with the exception of hallucinogens, with the fact

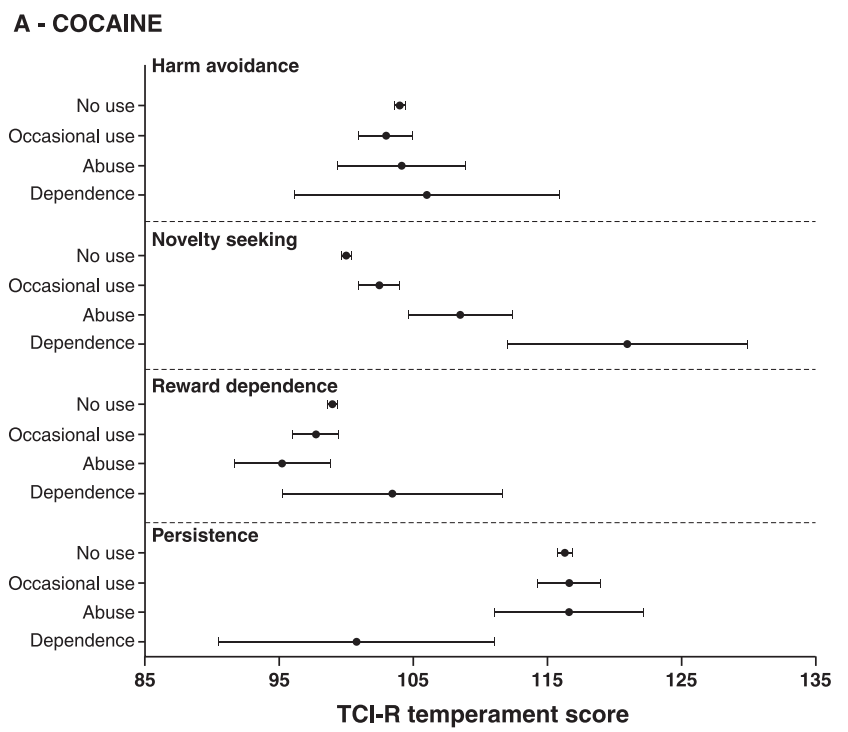

that exploratory excitability was not relevant, whereas extravagance and impulsiveness increased substantially with increasing drug involvement. HA scores were lower in individuals who occasionally use and abuse alcohol and cannabis, as well as in occasional hallucinogen users, but increased substantially $(d=0.8)$ with the severity of benzodiazepine use. ST was higher in individuals that showed abusive patterns of hallucinogen use and dependence patterns of benzodiazepine use, but not among cannabis users. Other findings include lower $\mathrm{CO}$ scores in participants with alcohol dependence and cocaine abuse; lower SD scores among those with cocaine abuse and dependence and those with cannabis dependence; declining SD scores with decreasing sever-

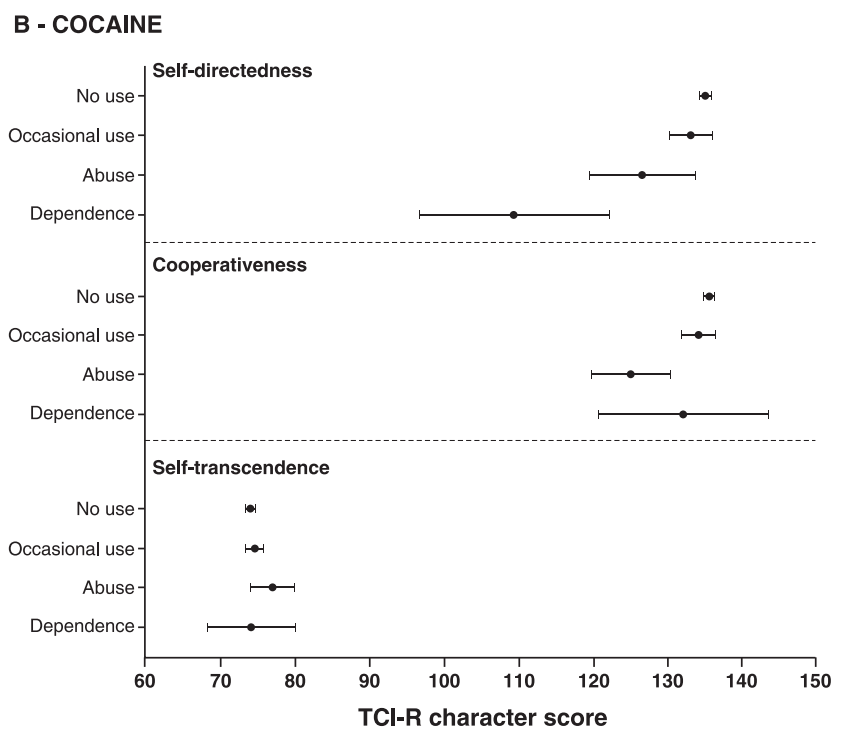

Figure 4 Temperament and character mean scores (dots) and Bonferroni-corrected 95\% confidence intervals (bars) in relation to patterns of cocaine involvement. TCl-R $=$ Temperament and Character Inventory - Revised. 


\section{A - HALLUCINOGENS}

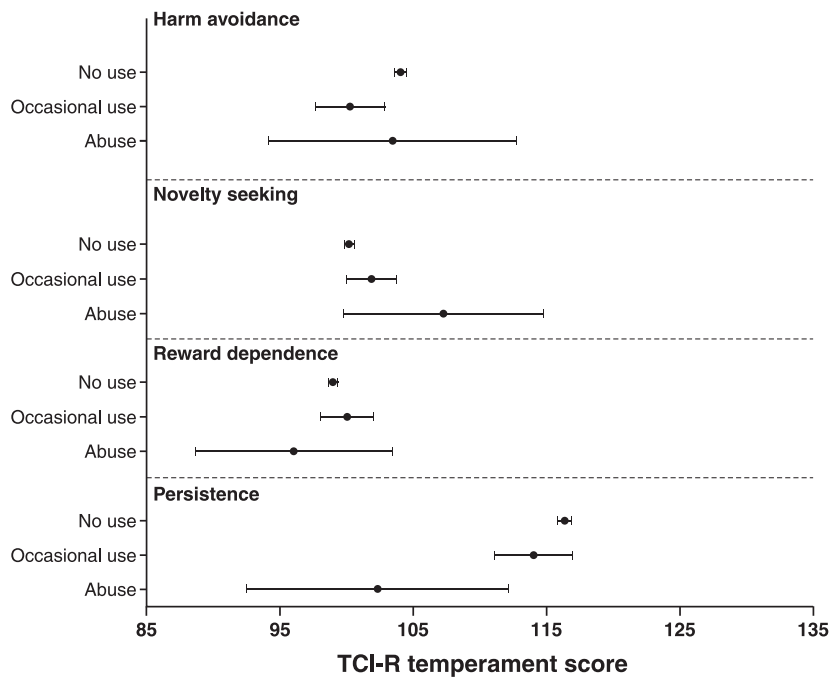

B - HALLUCINOGENS

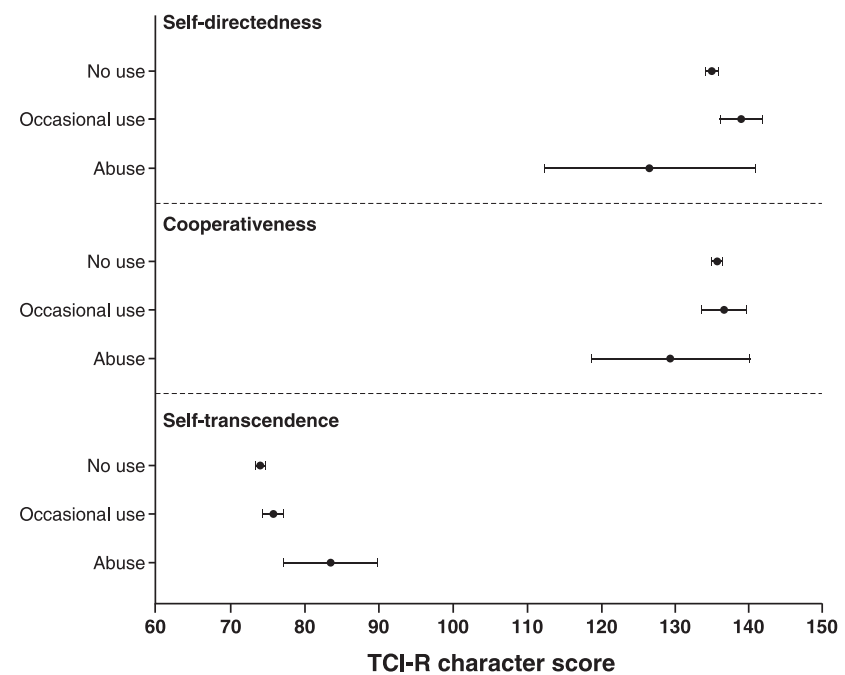

Figure 5 Temperament and character mean scores (dots) and Bonferroni-corrected 95\% confidence intervals (bars) in relation to patterns of hallucinogens involvement. TCI-R $=$ Temperament and Character Inventory - Revised.

ity of benzodiazepine use; higher RD scores among those with occasional cannabis use and cannabis dependence; and lower PS scores in occasional users of cocaine.

On comparison with similar studies, we found a few inconsistencies between our results and the findings obtained by other authors. For example, Le Bon et al., ${ }^{21}$ Allnutt et al., ${ }^{19}$ and Milivojevic et al. ${ }^{28}$ found higher $\mathrm{HA}$ scores in alcoholic inpatients and prisoners, while subjects with alcohol dependence were not different from controls in our sample. This contrast may be explained by the differences in sampling procedures: the aforementioned studies were mostly based on clinical or specific samples (such as prisoners) that may have selected participants with higher alcohol morbidity and comorbid disorders, while our availability sample of average internet users is bound to be more heterogeneous and, consequently, less severe. Some studies have reported that subjects with alcohol dependence tend to show higher SD scores than users of other drugs, ${ }^{19,37}$ an aspect not replicated in our data. However, the main finding of high NS scores associated with addiction ${ }^{28}$ has been confirmed, but the profile of high HA was clearly more pronounced in benzodiazepine addiction than in alcoholism in our sample.

Relevant methodological issues set this study apart from those previously conducted in advancing the understanding of substance use and its relations with temperament traits. First, this is the largest study ever conducted to examine the relationship between temperament and character traits and patterns of substance use and misuse in a community-based sample. Second, to the best of our knowledge, this is the first study that evaluates personality traits using $\mathrm{TCl}-\mathrm{R}$ in relation to benzodiazepine patterns of use. Moreover, the ASSIST scale used herein assesses the individual's involvement with the substances of abuse and allows characterization of transitions in the spectrum from occasional use to addiction, as well as comparison with drug-naïve subjects. Finally, and most importantly, the data were collected using a web survey design, which may be advantageous in comparison to traditional face-to-face survey designs for issues as delicate as substance use. $^{38,39}$ It is worth noting that: the quality of the data collected via web surveys is consistent with that of data obtained using pen-and-paper versions of instruments; data transfer mistakes are not expected to occur with web surveys; they enable collection of data from heterogeneous and large samples; and motivation by spontaneous participation is present, especially when personalized feedback is provided, as in the system used for this study. ${ }^{29}$

Two further limitations of the sampling procedure adopted in the present study are worth mentioning. The first concerns the non-representativeness of the resulting sample. To respond to our web survey, one had to, at least, 1) know of its existence, 2) be motivated, for whatever reason, to participate, and 3) have access to a computer connected to the internet. Furthermore, even if the referred prerequisites were fulfilled, the respondent was required to answer the validity items correctly during the survey process to be included in the sample. The second limitation concerns the non-availability of data regarding the participants that were excluded due to incorrect responses to the validity checks. The lack of such information may have overshadowed the effect of intervening variables, such as sociodemographic aspects, in the study. The final sample of this study is likely to be composed of individuals with motivation to respond to the survey attentively and who necessarily had access to the technology required to access our website. Therefore, one must take these aspects into consideration when interpreting our results.

Finally, the information presented herein has clinical and public health implications. From a clinical standpoint, 
A - ETHANOL

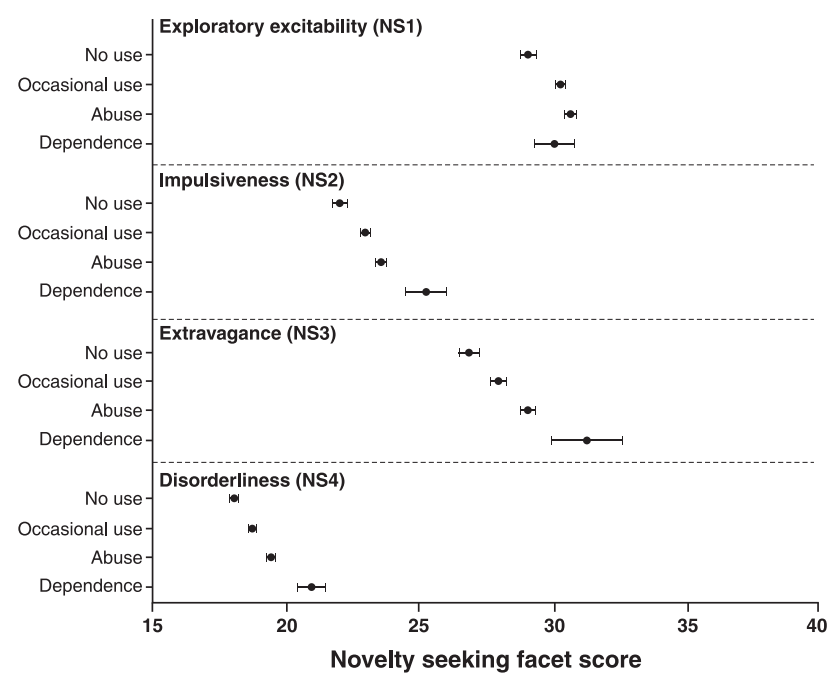

C -BENZODIAZEPINES

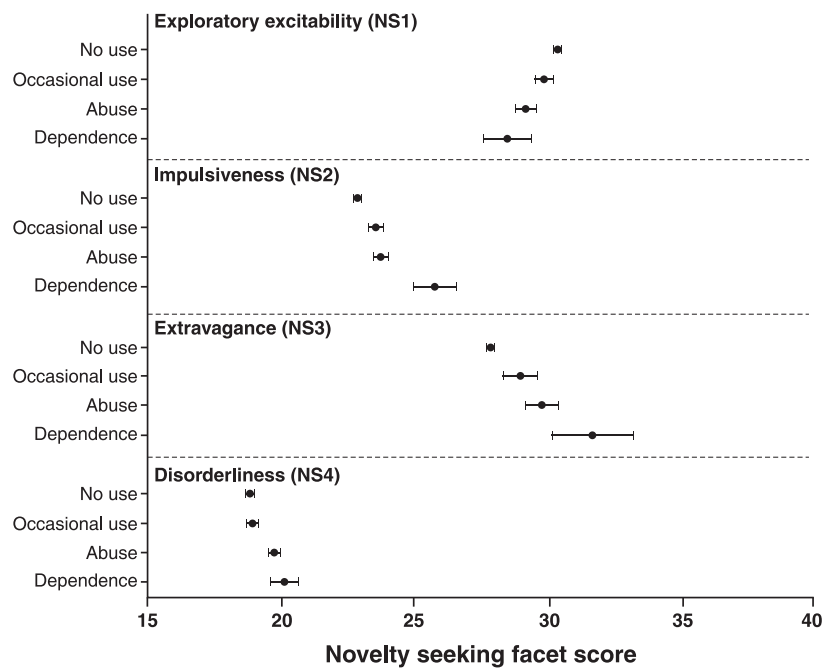

B - CANNABIS

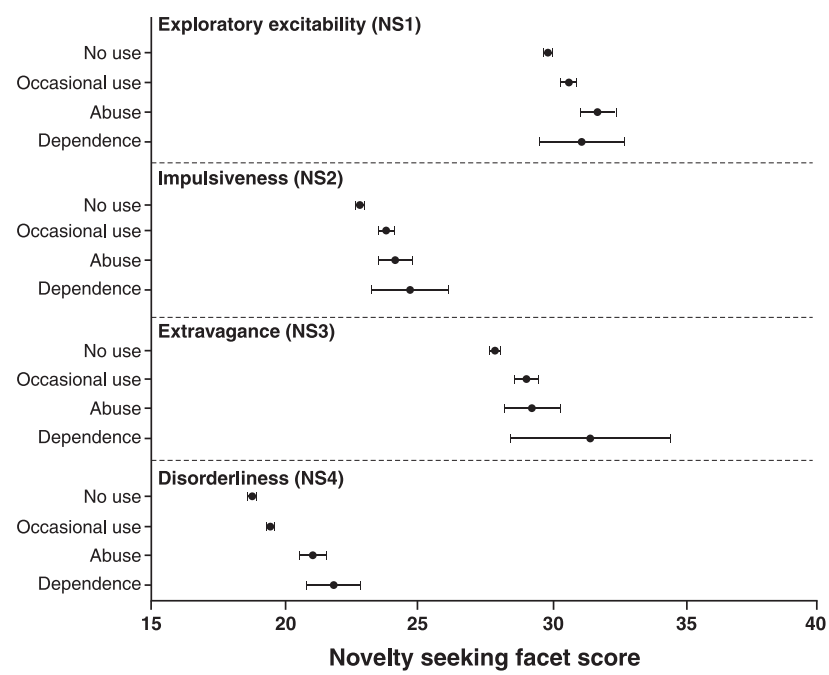

D - COCAINE

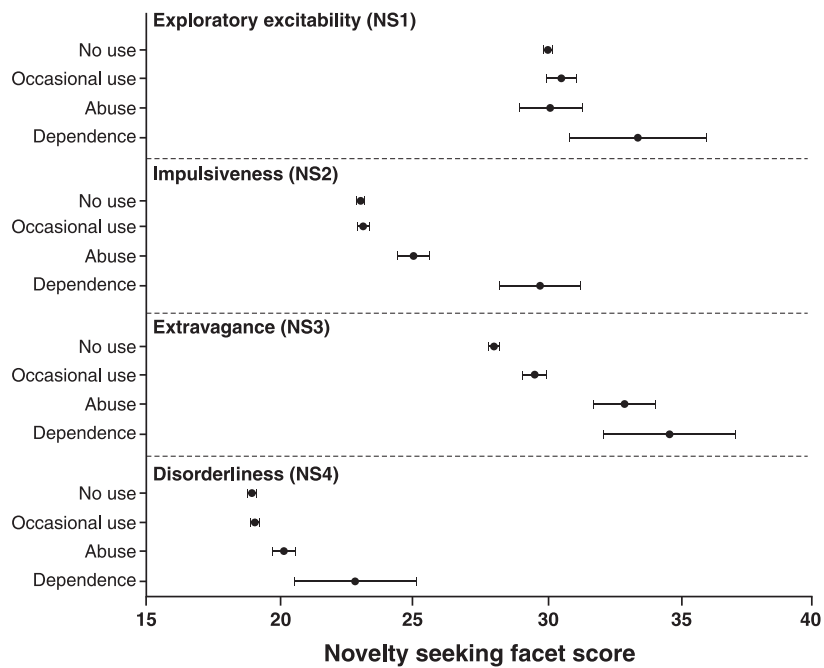

Figure 6 Novelty seeking facets mean scores (dots) and Bonferroni-corrected 95\% confidence intervals (bars) in relation to patterns of drug involvement. TCl-R = Temperament and Character Inventory - Revised.

associations between personality traits and substance use patterns may be helpful in understanding the clinical heterogeneity observed among people with substance use disorders. For example, while most substance users may display higher levels of impulsiveness and extravagance (facets of NS), hallucinogen users also (and are particularly prone to) exhibit thoughts and feelings that overcome the limits of the individual self and its desires in spiritual contemplation and realization, and benzodiazepine users are more prone to show avoidant behavior in the face of threats. From a public health perspective, these individual differences (and communalities) may be of particular importance in the development of anti-drug campaigns that target both the general public and specific groups, i.e., if increased NS is a general tendency associated with substance use, it may be relevant to take it into account when designing contexts and arguments that "novelty seekers" may relate to; conversely, if benzodiazepine users are the target audience of an intervention, it may be pertinent to establish a relation to $\mathrm{HA}$ tendencies.

In conclusion, NS, particularly due to impulsiveness and extravagance, was associated with increased drug involvement from experimentation to dependence of all drugs assessed in this study, although to a lesser extent in benzodiazepines and hallucinogens. The profile of benzodiazepine use was clearly different from that of other drugs, due to its association with higher HA and ST and lower SD. SD was only significantly affected at the level of dependence for most drugs. The identification of these associations between temperament, character, and severity patterns of drug abuse may be useful in guiding 
psychological and psychiatric intervention, educational programs, and public health strategies crucial to the prevention and management of drug addiction.

\section{Acknowledgements}

This study was supported by a public grant from DECIT/ SCTIE-MS via CNPq and Fundação de Amparo à Pesquisa do Estado do Rio Grande do Sul (FAPERGS) (protocol number 10/0055-0, PRONEX/Conv. 700545/ 2008). RSJ, HWC, DRL, and EE are research fellows from Conselho Nacional de Desenvolvimento Científico e Tecnológico (CNPq).

\section{Disclosure}

The authors report no conflicts of interest.

\section{References}

1 Zentner M, Bates JE. Child temperament: an integrative review of concepts, research programs, and measures. Eur J Dev Sci. 2008;2:7-37.

2 Matthews G, Deary IJ, Whiteman MC. Personality Traits. Cambridge: Cambridge University Press; 2009. p. 1-40.

3 Clark LA. Temperament as a unifying basis for personality and psychopathology. J Abnorm Psychol. 2005;114:505-21.

4 Lara DR, Pinto O, Akiskal K, Akiskal HS. Toward an integrative model of the spectrum of mood, behavioral and personality disorders based on fear and anger traits: I. Clinical implications. J Affect Disord. 2006;94:67-87.

5 Verheul R, van den Brink W. Causal pathways between substance use disorders and personality pathology. Austr Psychol. 2005; $40: 127-36$

6 Zilbermann ML, Tavares H, el-Guebaly N. Relationship between craving and personality in treatment-seeking women with substancerelated disorders. BMC Psychiatry. 2003;3:1.

7 Creemers HE, Dijkstra JK, Vollebergh WA, Ormel J, Verhulst FC, Huizink AC. Predicting life-time and regular cannabis use during adolescence; the roles of temperament and peer substance use: the TRAILS study. Addiction. 2010;105:688-704.

8 Cloninger CR. Neurogenic adaptive mechanisms in alcoholism. Science. 1987;236:410-16.

9 Caspi A, Begg D, Dickson N, Harrington H, Langley J, Moffitt TE, et al. Personality differences predict health-risk behaviors in young adulthood: evidence from a longitudinal study. J Pers Soc Psychol. 1997;73:1052-63.

10 Caspi A. The child is father of the man: Personality continuities from childhood to adulthood. J Pers Soc Psychol. 2000;78:158-72.

11 Krueger RF, Hicks BM, Patrick CJ, Carlson SR, Jacono WG, Mcgue M. Etiologic connections among substance dependence, antisocial behavior, and personality: modeling the externalizing spectrum. J Abnorm Psychol. 2002;111:411-24.

12 Krueger RF, Markon KE, Patrick CJ, Benning S, Kramer M. Linking antisocial behavior, substance use and personality: towards a comprehensive quantitative model of adult externalizing spectrum. J Abnorm Psychol. 2007;116:645-66.

13 Zuckerman M. The sensation seeking motive. Progr Exp Pers Res. 1974;7:79-148.

14 Roberti JW. A review of behavioral and biological correlates of sensation seeking. J Res Pers. 2004;38:256-79.

15 Desrichard O, Denarié V. Sensation seeking and negative affectivity as predictors of risky behaviors: a distinction between occasional versus frequent risk-taking. Addict Behav. 2005;30:1449-53.

16 Chakroun N, Johnson El, Swendsen J. Mood and personality-based models of substance use. Psychol Addict Behav. 2010;24:129-36.
17 Ball SA, Carroll KM, Rounsaville BJ. Sensation seeking, substance abuse, and psychopathology in treatment seeking and community cocaine abusers. J Consult Clin Psychol. 1994;62:1053-7.

18 Khan AA, Jacobson KC, Gardner CO, Prescott CA, Kendler KS. Personality and comorbidity of common psychiatric disorders. $\mathrm{Br} J$ Psychiatry. 2005;1869:190-6.

19 Allnutt S, Wedgwood L, Wilhelm K, Butler T. Temperament, substance use and psychopathology in a prisoner population: implications for treatment. Aust N Z J Psychiatry. 2008;42:969-75.

20 Vukov M, Baba-Milkic N, Lecic D, Mijalkovic S, Marinkovic J. Personality dimensions of opiate addicts. Acta Psychiatr Scand. 1995;91:103-7.

21 Le Bon O, Basiaux P, Streel E, Tecco J, Hanak C, Hansenne M, et al. Personality profile and drug of choice: a multivariate analysis using Cloninger's $\mathrm{TCl}$ on heroin addicts, alcoholics, and a random population group. Drug Alcohol Depend. 2004;73:175-82.

22 Masse LC, Tremblay RE. Behavior of boys in kindergarten and the onset of substance use during adolescence. Arch Gen Psychiatry. 1997;54:62-8.

23 Lara DR, Antoniolli E, Frozi J, Schneider R, Ottoni GL. Distinct personality traits associated with intake of coffee, tea and cola drinks and smoke. J Caffeine Res. 2011;1:101-8.

24 World Health Organization (WHO). International statistical classification of diseases and related problems. 10th ed. Geneva; 1993. p. 62-77.

25 Patrick CJ, Bernat EM. The construct of emotion as a bridge between personality and psychopathology. In: Krueger RF and Tackett JL, editors. Personality and Psychopathology. New York: Guilford Press; 2006. p. 174-209.

26 Cloninger CR, Svrakic DM, Pzyribeck TR. A psychobiological model of temperament and character. Arch Gen Psychiatry. 1993;50:97590.

27 Spalletta G, Bria P, Caltagirone C. Differences in temperament, character and psychopathology among subjects with different patterns of cannabis use. Psychopathology. 2007;40:29-34.

28 Milivojevic D, Milovanovic SD, Jovanovic M, Svrakic DM, Svrakic NM, Svrakic SM, et al. Temperament and character modify risk of drug addiction and influence choice of drugs. Am $\mathrm{J}$ Addict. 2012;21:462-7.

29 Lara DR, Ottoni GL, Brunstein MG, Frozi J, de Carvalho HM, Bisol LW. Development and validity data of the Brazilian Internet Study on Temperament and Psychopathology (BRAINSTEP). J Affect Disord. 2012;141:390-8.

30 Gonçalves DM, Cloninger CR. Validation and normative studies of the Brazilian Portuguese and American versions of the Temperament and Character Inventory - Revised (TCI-R). J Affect Disord. 2010;124:126-33.

31 Henrique IF, De Micheli D, Lacerda RB, Lacerda LA, Formigoni ML. Validação da versão brasileira do teste de triagem do envolvimento com álcool, cigarro e outras substâncias (ASSIST). Rev Assoc Med Bras. 2004;50:199-206.

32 de Carvalho HW, Andreoli SB, Jorge MR. Saúde geral: evidências de diferenças relacionadas ao sexo. Aval Psicol. 2011;10:173-9.

33 Andrade L, Walters EE, Gentil V, Laurenti G. Prevalence of ICD-10 mental disorders in a catchment area in the city of São Paulo, Brazil. Soc Psychiatry Psychiatry Epidemiol. 2002;37:316-25.

34 Kessler RC, Chiu WT, Demler O, Merikangas KR, Walters EE. Prevalence, severity, and comorbidity of 12-month DSM-IV disorders in the National Comorbidity Survey replication. Arch Gen Psychiatry. 2005;62:617-27.

35 Bauman A, Phongsavan P. Epidemiology of substance use in adolescence: prevalence, trends and policy implications. Drug Alcohol Depend. 1999;55:187-207.

36 Andrade LHSG, Viana MC, Silveira CM. Epidemiologia dos transtornos psiquiátricos na mulher. Rev Psiquiatr Clin. 2006;33:43-54.

37 Evren C, Evren B, Yancar C, Erkiran M. Temperament and character model of personality profile of alcohol and drug-dependent inpatients. Compr Psychiatry. 2007;48:283-8.

38 Turner CF, Ku L, Rogers SM, Lindberg LD, Pleck JH, Sonenstein FL. Adolescent sexual behavior, drug use, and violence: increased reporting with computer survey technology. Science. 1998;280:867-73.

39 Reimers S. The BBC internet study: general methodology. Arch Sex Behav. 2007;36:147-61. 